\title{
Medication-overuse headache: a widely recognized entity amidst ongoing debate
}

\author{
Nicolas Vandenbussche ${ }^{1 *}$ D, Domenico Laterza ${ }^{2}$, Marco Lisicki ${ }^{3}$, Joseph Lloyd ${ }^{4}$, Chiara Lupi ${ }^{5}$, Hannes Tischler ${ }^{6}$, \\ Kati Toom ${ }^{7,8}$, Fenne Vandervorst ${ }^{9}$, Simone Quintana ${ }^{10}$, Koen Paemeleire ${ }^{11}$ and Zaza Katsarava ${ }^{12}$
}

\begin{abstract}
Medication overuse in primary headache disorders is a worldwide phenomenon and has a role in the chronification of headache disorders. The burden of disease on individuals and societies is significant due to high costs and comorbidities. In the Third Edition of the International Classification of Headache Disorders, medication-overuse headache is recognized as a separate secondary entity next to mostly primary headache disorders, although many clinicians see the disease as a sole complication of primary headache disorders. In this review, we explore the historical background of medicationoveruse headache, its epidemiology, phenomenology, pathophysiology and treatment options. The review explores relevant unanswered questions and summarizes the current debates in medication-overuse headache.
\end{abstract}

Keywords: Medication-overuse headache, Review, Nosology

\section{Background}

Overuse of symptomatic medication is a common problem in patients with primary headache syndromes $[1,2]$. Headache syndromes such as migraine or tension-type headache cause painful experiences and significant disability in patients. The use of analgesics is therefore justifiable when correctly utilized. For more than 50 years, clinicians have recognized and reported on headache chronification occurring during a period of frequent use of analgesics. The underlying consensus for the entity of medication-overuse headache $(\mathrm{MOH})$ consists of a deterioration of a pre-existing headache syndrome whilst overusing one or several types of acute painkilling treatments. $\mathrm{MOH}$ is widely accepted and recognised in the neurological and headache community nowadays, although the entity keeps raising important questions. Debates on the pathophysiological mechanisms, definitions of overuse and the nosology of $\mathrm{MOH}$ are ongoing. This review presents the current state of literature and knowledge on $\mathrm{MOH}$. It provides an overview of the history, clinical features, epidemiology of $\mathrm{MOH}$, an update on the current understanding of the underlying

\footnotetext{
* Correspondence: Nicolas.vandenbussche@kcl.ac.uk

${ }^{1}$ Headache Group, Department of Basic and Clinical Neuroscience, King's College London, and NIHR-Wellcome Trust King's Clinical Research Facility, King's College Hospital, Denmark Hill, London SE5 9PJ, UK

Full list of author information is available at the end of the article
}

neurobiological mechanisms and treatment, before discussing the key topics in the controversies surrounding $\mathrm{MOH}$.

\section{MOH in historical perspective}

The first descriptions of MOH date back to 1930s, when multiple authors started to associate prolongation of migraine with ergotamine-overuse [3-8]. Chronic headache following overuse of ergotamine was clearly defined by Peters and Horton in 1951 [9]. They reported on 52 migraine patients who developed daily headache after daily use of ergotamine and noted improvement after the drug was stopped. The same authors published their withdrawal protocol in 1963 [10]. The first ergotamine withdrawal protocols were proposed independently by Graham, Friedman and Lippmann in 1955 [3, 6-8]. In the 1970s, multiple authors wrote on the association between overuse of mixed analgesics, including those based on ergotamine, barbiturates and codeine, and headache progression [11, 12]. In 1982, Mathew et al. outlined that overuse of analgesics contributed to the transformation of episodic migraine (EM) into daily headaches and a few years later the same group introduced the term "transformed or evolutive migraine" to describe the entity $[3,13,14]$.

The first edition of the International Classification of Headache Disorders (ICHD) was published in 1988 which introduced the term "drug-induced headache". It 
also introduced and specified the entities "ergotamine-induced headache", "analgesics abuse headache" and "other substances" [15]. This was based on the experience with overuse of analgesics and ergots only. After the introduction of triptans, it became clear that this class of drugs could also induce headache deterioration if used excessively [16-18]. In 1994 Silberstein et al. proposed criteria for "transformed migraine", since transformation of EM to daily or almost-daily head pain ( $>15$ days/month) was associated with medication overuse [3, 19].

The term "medication-overuse headache" was first introduced in the second edition of the ICHD in 2004 [20]. It also defined MOH subtypes induced by simple analgesics, combination-analgesics, ergots, triptans and opioids. The diagnostic criteria included a mandatory prerequisite that the headache syndrome resolved or reverted to the previous pattern within 2 months after discontinuation of the overused drug. This caused the entity of definite $\mathrm{MOH}$ to be diagnosed retrospectively and more difficult to handle in clinical practice [20]. The criterion was changed in 2006 when a board of experts published revisions by consensus and introduced a broader concept of $\mathrm{MOH}$, in which the diagnosis was based on headache frequency (equal to or greater than 15 days/month) and overuse of headache medication, but did not require the headache to improve after withdrawal [21]. This criterion was omitted again in the latest and current Third Edition of the International Classification of Headache Disorders (ICHD-3) [22].

\section{Current definitions}

In ICHD-3, chronic headache syndromes are defined by expert consensus as headache disorders that share characteristics with pre-existing headache syndromes, occur for a certain amount of time (at least 3 months in e.g. chronic tension-type headache $(\mathrm{CTTH})$, chronic migraine $(\mathrm{CM})$; or at least 1 year in e.g. chronic trigeminal autonomic cephalalgia (TAC)) and have an additional time-criterion (e.g. headache days per month in CTTH and $\mathrm{CM}$, or the absence of remissions for more than 3 months in TAC's). $\mathrm{MOH}$ is found in ICHD-3 under subsection 8.2 as a chronic headache disorder secondary to a pre-existing headache syndrome. It is stipulated as a consequence of regular overuse of drugs for the acute treatment of headache. To establish the diagnosis, patients have to use symptomatic headache medication on more than 10 or more than 15 days per month, depending on the drug class, for more than 3 months. $\mathrm{MOH}$ has 8 subforms - $\mathrm{MOH}$ induced by ergotamine, triptans, analgesics including paracetamol, aspirin and other non-steroidal anti-inflammatory drugs (NSAIDs), opioids, combination analgesics, unspecified multiple drug classes and others (Table 1) [22].

Although considered a general rule in the past, it is now well stated in the classification that $\mathrm{MOH}$ usually, but not invariably, resolves once the overuse is stopped $[22,23]$. As with all secondary headache syndromes in ICHD-3, there is no longer a necessary requirement of remission or substantial improvement of the underlying causative disorder for the diagnosis to be made. Therefore, when $\mathrm{MOH}$ is confirmed by using the medical history of the patient, a two-fold diagnosis is made: the first one entailing the primary headache syndrome that resulted in drug overuse, the second one $\mathrm{MOH}$ [23].

\section{Epidemiology}

The prevalence of chronic headache is $4 \%$ to $5 \%$, with an incidence of $3 \%$ per year [24, 25]. The incidence of new-onset CM in patients with EM is around 2.5\% per year [24, 26]. Even higher incidence rates up to $14 \%$ were reported from a tertiary centre [27]. Prevalence rates for $\mathrm{MOH}$ in the general population level are situated between 1 and $2 \%$, with a range between $0.5 \%$ and $7.2 \%$ [28]. The highest prevalence has been shown in Russia (7.2\%) [29]. Knowledge about prevalence and socio-economic burden in lesser developed countries has been very limited for a long time, although studies have been published lately for prevalence in Africa (Zambia 7.1\%; Ethiopia 0.7\%), Latin America (Brazil $1.4 \%$, Colombia $4.3 \%$ ) and Asia (Korea $0.5 \%$; China $0.6 \%$ ) [30-35] . MOH is estimated to affect around 63 million people worldwide [35-37]. The prevalence of medication overuse is higher in studies from headache specialist centers, with numbers ranging from $30 \%$ to $50 \%$ of patients [38-40].

A systematic review of epidemiological studies found that $\mathrm{MOH}$ is most common among middle-aged adults from 30 to 50 years of age, and predominant in females in the majority of studies. The male to female ratio is around 1 to $3-4$ [28, 36, 41-43]. Among U.S. children and adolescents, the prevalence of $\mathrm{CM}$ was found to be $0.79 \%$ if medication overuse was excluded, and $1.75 \%$ if it was included [44, 45]. Prevalence of $\mathrm{MOH}$ was greater in girls than boys [44]. Furthermore, between $21 \%$ and $52 \%$ of pediatric patients with chronic headache met the criteria for $\mathrm{MOH}[45,46]$. Worldwide, the prevalence of $\mathrm{MOH}$ in pediatric samples was $3.3 \%, 0.3 \%, 0.5 \%$ and $1.6 \%$ in Italy, Taiwan, Norway and Canada respectively [37, 47-50]. In the elderly population, studies from multiple headache centers found that around $35 \%$ of patients older than 64 years were overusing medication $[51,52]$. Reports on prevalence of $\mathrm{MOH}$ in specific populations and minorities have been published. In Europe, certain minorities or ethnic groups, such as first-generation migrants, show higher than expected rates of $\mathrm{MOH}$. 
Table 1 International Classification of Headache Disorders Third Edition (ICHD-3) Criteria for Medication-Overuse Headache $(\mathrm{MOH})[22]$

8.2 Medication-overuse headache $(\mathrm{MOH})$

A. Headache occurring on $\geq 15$ days/month in a patient with a pre-existing headache disorder

B. Regular overuse for $>3$ months of one or more drugs that can be taken for acute and/or symptomatic treatment of headache

C. Not better accounted for by another ICHD-3 diagnosis. 8.2.1 Ergotamine-overuse headache

A. Headache fulfilling criteria for 8.2 Medication- overuse headache

B. Regular intake of ergotamine on $\geq 10$ days/month for $>$ 3 months.

8.2.2 Triptan-overuse headache

A. Headache fulfilling criteria for 8.2 Medication- overuse headache

B. Regular intake of one or more triptans, 1 in any formulation, on $\geq 10$ days/month for $>3$ months.

8.2.3 Non-opioid analgesic-overuse headache

8.2.3.1 Paracetamol (acetaminophen)-overuse headache

A. Headache fulfilling criteria for 8.2 Medication- overuse headache

B. Regular intake of paracetamol on $\geq 15$ days/ month for $>$ 3 months.

8.2.3.2 Non-steroidal anti-inflammatory drug (NSAID)- overuse headache

A. Headache fulfilling criteria for 8.2 Medication- overuse headache

B. Regular intake of one or more non-steroidal antiinflammatory drugs (NSAIDs) (other than acetylsalicylic acid) on $\geq 15$ days/month for $>3$ months.

8.2.3.2.1 Acetylsalicylic acid-overuse headache

A. Headache fulfilling criteria for 8.2 Medication- overuse headache

B. Regular intake of acetylsalicylic acid on $\geq 15$ days/ month for $>3$ months.

8.2.3.3 Other non-opioid analgesic-overuse headache

A. Headache fulfilling criteria for 8.2 Medication- overuse headache

B. Regular intake of a non-opioid analgesic other than paracetamol or non-steroidal anti-inflammatory drugs (including acetylsalicylic acid) on $\geq 15$ days/month for $>3$ months.

8.2.4 Opioid-overuse headache

A. Headache fulfilling criteria for 8.2 Medication- overuse headache

B. Regular intake of one or more opioids on $\geq 10$ days/month for $>3$ months.

8.2.5 Combination-analgesic-overuse headache

A. Headache fulfilling criteria for 8.2 Medication- overuse headache

B. Regular intake of one or more combination-analgesic medications on $\geq 10$ days/month for $>3$ months.

8.2.6 Medication-overuse headache attributed to multiple drug classes not individually overused

A. Headache fulfilling criteria for 8.2 Medication- overuse headache

B. Regular intake of any combination of ergotamine, triptans, non-opioid analgesics and/or opioids on a total of $\geq 10$ days/month for $>3$ months without overuse of any single drug or drug class alone.

8.2.7 Medication-overuse headache attributed to unspecified or unverified overuse of multiple drug classes

A. Headache fulfilling criteria for 8.2 Medication- overuse headache

B. Both of the following: 1. regular intake of any combination of ergotamine, triptans, non-opioid analgesics and/or opioids on $\geq 10$ days/month for $>3$ months
Table 1 International Classification of Headache Disorders Third Edition (ICHD-3) Criteria for Medication-Overuse Headache $(\mathrm{MOH})[22]$ (Continued)

8.2.8 Medication-overuse headache attributed to other medication

A. Headache fulfilling criteria for 8.2 Medication- overuse headache

B. Regular overuse, on $\geq 10$ days/month for $>3$ months, of one or more medications other than those described above, 1 taken for acute or symptomatic treatment of headache.

Potential explanations for these findings include socioeconomic (e.g. use of healthcare), biological (e.g. genetic) or cultural reasons (e.g. language barriers) [53].

The burden of disease for $\mathrm{MOH}$ has been shown to be a worldwide problem. The disorder causes important negative social and economic effects in both rich and poor countries. Mean per-person annual costs were calculated at $€ 3561$ for medication overuse [54]. Not only economic factors, but also psychological and physical disability of chronic headache and $\mathrm{MOH}$ needs to be considered. The global campaign "Lifting the Burden" has contributed to the acquisition of new data and to the promotion of accurate epidemiological methods all over the world $[55,56]$. In the most recent issue of the Global Burden of Disease (GBD) in 2016, migraine became the second largest cause of disability, mainly because $\mathrm{MOH}$ was considered a sequela of migraine and tension-type headache [57].

\section{Risk factors}

Medication overuse was found to be an important risk factor for chronification of primary headaches [58]. A systematic review analysed twenty-nine studies and found differences in the risk of developing $\mathrm{MOH}$ and the type of used drug. The risk was lowest for triptans (relative risk (RR) 0.65) and ergotamine (RR 0.41) compared to combined analgesics. Triptans and ergotamine containing drugs were found more favorable when compared to opioids [59]. This is in line with Bigal et al. who reported that people using medication containing barbiturates or opiates had a two-fold higher risk of developing chronic headache than patients using single analgesics or triptans. In this study, NSAIDs were protective against developing chronic headache at low to moderate level of monthly headache days, but were associated with an increased risk of developing chronic headache in patients with a high level of monthly headache days (more than 10 days per month) [26].

An important risk factor for the development of $\mathrm{MOH}$ is predisposition for migraine or tension-type headache as an underlying biological trait. Migraine is the most common pre-existing headache disorder complicated by $\mathrm{MOH}$. Other pre-existing headache disorders can be complicated by $\mathrm{MOH}$ as well, such as tension-type headache or cluster headache [60]. Paemeleire et al. investigated the presence of $\mathrm{MOH}$ in patients suffering from 
cluster headache and found this complication only in patients also suffering with migraine or having at least a family history of migraine [61]. In addition, the clinical experience shows that the majority of patients suffering from cluster headache do not complicate into $\mathrm{MOH}$ although overuse of sumatriptan injections can lead to increased frequency of cluster attacks [62]. Patients with other chronic pain disorders who overuse painkillers for non-cephalic pain conditions do not seem to acquire chronic headache, unless they have a pre-existing history of a primary headache disorder $[63,64]$.

In a large prospective population-based study, Hagen et al studied 25.596 patients who did not suffer from chronic daily headache at baseline but had $\mathrm{MOH} 11$ years later $(n$ $=201,0.8 \%$ ) [65]. In this study, the following risk factors were found to be associated with the development of $\mathrm{MOH}$ : regular use of tranquilizers (odds ratio (OR) 5.2, 95\% confidence interval (CI) 3.0-9.0), combination of chronic musculoskeletal complaints, gastrointestinal complaints and Hospital Anxiety and Depression Scale (HADS) score $>=11$, physical inactivity (defined as $>=$ $3 \mathrm{~h}$ hard physical activity/week), and smoking (daily vs. never). Furthermore, migraine was a stronger risk factor for $\mathrm{MOH}$ than nonmigrainous headache. A strong association was found for a high-frequency headache defined as 7-14 days/months compared to absence of headache days. Non-modifiable risk factors for $\mathrm{MOH}$ were age younger than 50, female gender and low level of education. Interestingly, the authors found several risk factors for $\mathrm{MOH}$ (e.g. smoking, inactivity) that were not found to increase the risk for chronic daily headache without the overuse of analgesics. Therefore, the authors concluded that both entities might be pathogenetically distinct [65]. Lastly, Cevoli et al. detected a more than threefold increased risk of $\mathrm{MOH}$ if a family history of $\mathrm{MOH}$ or other substance abuse, such as drug or alcohol abuse, was present [66].

\section{Clinical features of $\mathrm{MOH}$}

A comprehensive medical history, clinical examination and the use of internationally accepted criteria and guidelines are the required tools for the diagnosis of $\mathrm{MOH}$. A confirmatory diagnostic test for $\mathrm{MOH}$ is currently not available. The headache phenotype of $\mathrm{MOH}$ may be indistinguishable from other forms of chronic daily headache. Moreover, the ICHD-3 criteria do not stipulate $\mathrm{MOH}$-specific clinical features (such as headache characteristics or associated symptoms). Awareness for potential secondary headache syndromes is required and 'red flags' have to be searched for in order to the avoid a false-positive diagnosis of $\mathrm{MOH}$ in escalating headache disorders, some of which may require medical imaging or lumbar puncture. In practice, an in-depth enquiry of headache types, frequency and especially drug use is always mandatory, as overuse of ergotamine, triptans, NSAIDs, opioids, or analgesic combinations entail different prognostic properties [24, 67].

\section{Comorbidities}

Comorbidity is the simultaneous existence of two or more different medical conditions. Comorbidities occur by chance, or by more than chance, suggesting a potential association, causality, common aetiological factors or common pathophysiological processes. In the field of $\mathrm{MOH}$, these terms are often difficult to appoint although researchers have found multiple associations.

Psychiatric comorbidities in $\mathrm{MOH}$ are frequent and have been studied extensively since the earliest descriptions of patients with $\mathrm{MOH}$ [68]. $\mathrm{MOH}$ and mood disorders such as anxiety and depression are thought to be comorbid disorders by more than chance [13, 69-71]. In the BIMOH study, a prospective interventional study, Hospital Anxiety and Depression Scale (HADS) scores were collected in patients with $\mathrm{MOH}$ (before and after a brief intervention) and controls. $\mathrm{MOH}$ patients were found to show significantly higher HADS scores for anxiety [72]. In the "COMOESTAS" trial, using HADS, $40.0 \%$ of $\mathrm{MOH}$ patients fulfilled the criteria for depression and $57.7 \%$ for anxiety [73]. The "Eurolight" trial, a cross-sectional study in the adult population of ten European Union countries, found similar results. The association was even stronger compared to a group of patients with migraine without overuse [74].

In the Sodium Valproate in Medication Overuse Headache Treatment (SAMOHA) study, a more extensive screening for psychopathological comorbidities was performed in $\mathrm{MOH}$ patients in comparison to patients with EM and healthy controls [71]. The rate of moderate to severe anxiety in $\mathrm{MOH}$ was significantly higher compared to EM patients and healthy controls. Values on the Leeds Dependency Questionnaire were significantly higher in $\mathrm{MOH}$ patients compared to EM patients, which indicates a greater susceptibility to drug dependency. When looked at the number of psychiatric disorders, $\mathrm{MOH}$ patients were more likely to have multiple psychiatric comorbidities.

An association between clinically relevant obsessive-compulsive disorder (OCD) and $\mathrm{MOH}$ was demonstrated [71]. Around 30\% of $\mathrm{MOH}$ patients are estimated to show clinical features of subclinical OCD on neuropsychological evaluation. Subclinical OCD may be an additional risk factor for headache chronification [75, 76]. Also, $\mathrm{MOH}$ can be associated to substance-related disorder spectrum, moreover since $\mathrm{MOH}$ and dependence share common neurobiological pathways, although $\mathrm{MOH}$ patients do not share common personality characteristics with drug addicts $[77,78]$.

For metabolic disorders, a couple of studies from North America on obesity found an increased risk of developing chronic headache, although in the European study by 
Hagen et al. no such association found $[69,79,80]$. In a Chinese cohort, an association between $\mathrm{MOH}$ and metabolic disturbances such as obesity and hypertension was shown in female patients [81]. Recent data on smoking, physical inactivity and obesity provided by a Danish cross-sectional analysis confirmed an association between $\mathrm{MOH}$ and those metabolic derangements although causality could not be proven [82]. In children, the association between obesity and chronic headache has been shown in observational studies, but the link with medication overuse is unclear [83, 84]. Lastly, patients with chronic headache and $\mathrm{MOH}$ present a high prevalence of sleep complaints [85].

\section{Pathophysiology}

A complete understanding of the pathophysiology of $\mathrm{MOH}$ currently does not exist [86-88]. Although the clinical aspects of $\mathrm{MOH}$ seem to be ambivalent, there is evidence for specific neurobiological aspects in $\mathrm{MOH}-$ models. Animal studies, genetic studies, structural and functional neuroimaging, and electrophysiological analyses have added to the current knowledge on the pathophysiology of $\mathrm{MOH}$ (Fig. 1).

Animal studies have shown changes in multiple physiological processes in the central nervous system (CNS) after repetitive administration of analgesics. Chronic sumatriptan exposure produces long-lasting increased susceptibility to evoked cortical spreading depression (CSD) due to lower threshold [89-91]. Upregulation of vaso-active and pro-inflammatory mediators such as calcitonin gene-related peptide (CGRP), substance P, and nitric oxide synthase were found in trigeminal ganglia [92, 93]. An expansion of the receptive nociceptive field, a decreased nociceptive threshold and decreased noxious inhibitory control have been reported [91, 94]. Furthermore, chronic exposure to analgesics was found to increase the excitability of neurons in the central nucleus of the amygdala, which may conceptualise the development of anxiety or depression in patients with $\mathrm{MOH}$ [95].

The serotonergic modulating system is presumably affected by chronic analgesic use, resulting in neuronal hyperexcitability, enhanced CSD and trigeminal nociception, caused by increased expression of pro-nociceptive serotonin 2A (5HT-2A) receptor binding sites and a decrease in the production of serotonin in the CNS [96-98]. In analogy to the findings in animals, an upregulation of 5HT-2 receptors on platelet membranes during analgesic abuse and lower platelet levels of serotonin were found, probably caused by suppressed serotonin transport [99].

Genetic studies have been performed in $\mathrm{MOH}$ although high-quality evidence for genetic traits is currently lacking. In a recent systematic review, Cargnin et al. described candidate polymorphic variants in genes of the dopaminergic gene system (DRD4, DRD2, SLC6A3), and genes related to drug-dependence pathways (WSF1, BDNF, ACE, HDAC3). The authors concluded that these traits are

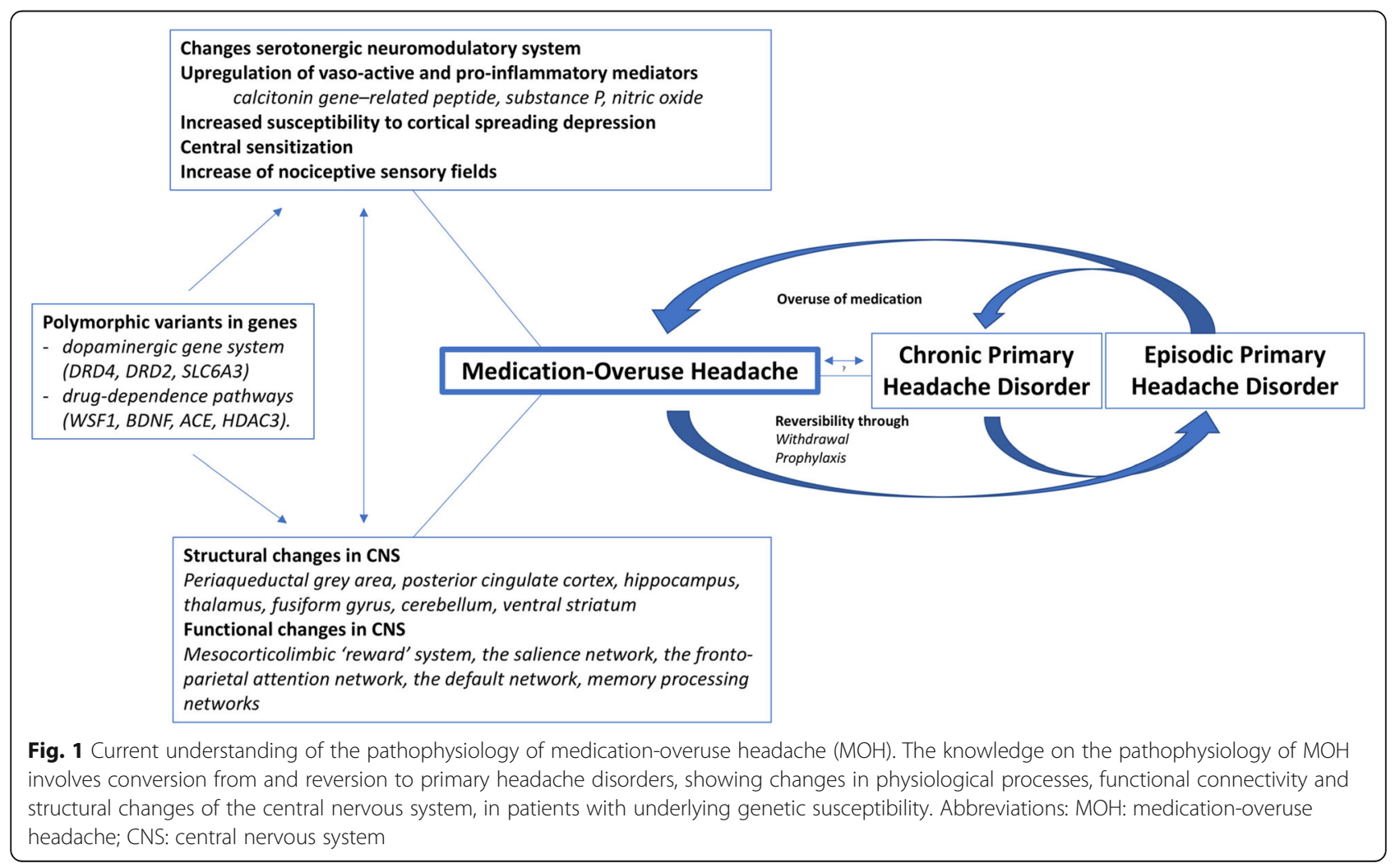


potential risk factors for $\mathrm{MOH}$ susceptibility or determinants of monthly drug consumption [100-107].

Research shows that central sensitization has a major role in the pathophysiology of $\mathrm{MOH}[88,108]$. Using somatosensory evoked potentials comparing cortical responses in $\mathrm{MOH}$ patients with responses in healthy volunteers and episodic migraineurs, hypersensitivity (a sign of central sensitization) and hyper-responsiveness of the cerebral cortex were shown in $\mathrm{MOH}$ patients as potential markers of altered functioning. The authors suggested that the somatosensory cortex in $\mathrm{MOH}$ patients is somehow "locked" in a kind of pre-ictal state [109, 110].

More recently, a cohort of $\mathrm{MOH}$ patients was followed during a 12 month period, evaluating central sensitization through pain-perception assessment. The authors found evidence of central sensitization at baseline, but most importantly, the study permitted to expose the slow progression towards normalization of sensory processing after detoxification during the extended follow-up window. This adds to the importance of detoxification and observation after withdrawal in order to prevent relapses [111].

Over the last decade, imaging studies have increased the knowledge of structural alterations and physiological events in $\mathrm{MOH}$. Structural imaging studies performed by separate groups have found increased gray matter volume in following areas: periaqueductal gray (PAG) area, posterior cingulate cortex, hippocampus, thalamus, fusiform gyrus, cerebellum and ventral striatum $[87,88,112]$. Less volume was found in the orbitofrontal cortex (OFC), anterior cingulate cortex, left middle occipital gyrus, insula and precuneus $[87,88,112]$. These structures are involved in pain modulation and processing, cognition, affective behavior, addiction and awareness [87]. A recent study described disturbances in white matter integrity in the insular cortex and in the parietal operculum [113]. It has to be noted however that not all studies found the same morphologic differences in the brains of $\mathrm{MOH}$ patients with migraine, including those comparing scans before and after withdrawal $[87,114,115]$.

Functional imaging has shown altered functional connectivity in pain processing areas, the mesocorticolimbic 'reward' system, the salience network, the fronto-parietal attention network, the default network and memory processing networks [87, 113, 115-118]. The mesocorticolimbic dopaminergic 'reward' system, characterized by structures such as the ventromedial prefrontal cortex (VMPFC), the nucleus accumbens and the substantia nigra/ventral tegmental area, seems to be affected in $\mathrm{MOH}$, linking psychiatric characteristics such as dependence mechanisms and addictive components to the disorder [87, 117, 118].

It is noteworthy that, in $\mathrm{MOH}$, changes of functional connectivity and structure may be reversible in some but not all regions and sometimes normalize after treatment
[87]. By using [18F] fluorodeoxyglucose-Positron emission tomography (FDG-PET), it was detected how several pain processing regions in the brain were hypometabolic during medication overuse but recovered to normal metabolism after withdrawal. An exception to these findings was found in the OFC, a region linked with drug dependence and addiction. This region remained hypometabolic despite discontinuation of analgesics [119]. Other groups have confirmed changes in this region of interest. Reduction of gray matter volume in the OFC was correlated with headache days at follow-up, hereby exhibiting predictive capability in terms of poor response to treatment $[112,120]$. Non-responders to withdrawal therapy seemed to have less gray matter in the OFC on their pre-detoxification scan and that there was a positive correlation of gray matter in the OFC with response to treatment [121]. Interestingly, in a longitudinal study, $\mathrm{MOH}$ patients with clinical improvement after withdrawal had a significant decrease of previously increased gray matter in the midbrain (PAG, nucleus cuneiformis), whereas patients without improvement did not [121]. Another group found that VMPFC dysfunction is reversible and might be attributable to headache, whereas dysfunction observed in the mid-brain dopaminergic areas (substantia nigra/ventral tegmental area) are probably long-lasting and related to drug overuse $[116,117]$. In conclusion, the evidence provided in multiple studies shows that medication overuse causes changes to the CNS in people with an underlying susceptibility for progression. Changes in pain processing networks, dependence networks, sensitization and receptor density in the CNS presumably explain the clinical characteristics of the disorder.

\section{Treatment}

\section{Education and prevention}

$\mathrm{MOH}$ is often considered to be a preventable condition [122]. Instructing patients about the relationship between an excessive use of acute medications and headache progression is an important preventive measure. The results from multiple studies have shown that most $\mathrm{MOH}$ patients have little to no knowledge about excessive drug intake headache chronification. Many patients however received correct information, but often did not remember or had not fully understood the message [123-125]. As in other patients with chronic pain conditions, $\mathrm{MOH}$ patients seem mainly focused on the side effects related to the acute pain medications, including gastrointestinal bleeding, kidney damage, and liver impairment. They are often surprised when they learn that the excessive use of acute pain drugs might increase headache frequency, leading to $\mathrm{MOH}$ [126]. This is due to the fact that for many $\mathrm{MOH}$ patients the symptomatic medications are merely the drugs they need to relief 
their pain, and the only way that could bring relief to the impact on their lives [127].

According to this evidence, developing information campaigns and strategies to target patients at risk, preferably before $\mathrm{MOH}$ onset, represents an essential objective in headache medicine. In German headache centers, a brochure on medication overuse was effective in preventing the development of $\mathrm{MOH}$ in people with migraine and frequent medication use [128]. Primary care is the best setting for prevention and initial treatment of $\mathrm{MOH}$, since most $\mathrm{MOH}$ patients consult their general practitioner (GP) for headache (80\%) [129]. GPs can play a key role in providing patient education about medication use and modifiable risk factors, such as stress, daily smoking, physical inactivity, and obesity [82]. GPs are also capable of prescribing first-line headache prophylaxis in episodic patients when required.

$\mathrm{MOH}$ patients often bypass medical advice by using over-the-counter medication. A study recruited patients in pharmacies and found that only $14.5 \%$ were ever advised to limit intake frequency of acute headache treatments [130]. In a recent Swedish study investigating the knowledge of 326 pharmacists on headache treatment, only $8.6 \%$ demonstrated knowledge that overuse of all types of acute headache medications could lead to the development of $\mathrm{MOH}$ [131].

In 2016, the Danish national awareness campaign for $\mathrm{MOH}$ was conducted to reach the general public, GPs, and pharmacists. Online resources, print media, radio interviews, and a television broadcast were used to bring key messages such as overuse of pain medication can worsen headaches, pain medication should be used rationally, and medication overuse headache is treatable. The survey showed an increase in percentage of the public who knew about $\mathrm{MOH}$ [132].

\section{Withdrawal as the first phase of treatment}

Despite the large controversies about whether medication overuse should be regarded as a cause or a consequence of headache chronification, to date, the worldwide consensus agrees that (ideally complete) withdrawal of acute painkilling drugs is the approach of choice for the acute management of $\mathrm{MOH}$ patients [133-135]. In a recent randomized controlled open-label trial, complete discontinuation of acute medications came forward as the most effective detoxification program compared to restricted drug intake [136]. Drug discontinuation is advised in most headache treatment guidelines, including guidelines for primary care [137-139] . The crucial therapeutic aspect of withdrawal is that, on the one hand, it is an occasion for the physician to help the patient decrease or stop the use of acute medication, while potentially initiating a new preventive therapy. It is an opportunity for the patient to reconsider his or her headache history, to discover the link with medication overuse and to be guided by the physician in the process of withdrawal [140].

Drug discontinuation is performed variously in different headache clinics. In terms of timing, no studies have investigated the abrupt interruption versus the progressive cessation of the overused drugs, but it is widely agreed that for triptans, ergots, combination analgesics, simple analgesics, and NSAIDs the abrupt withdrawal is the treatment of choice, since these medications do not cause severe withdrawal symptoms [137]. On the opposite, a gradual drug reduction is the best option with barbiturates, benzodiazepines, and opioids [137]. Withdrawal symptoms (e.g. headache, nausea, vomiting, arterial hypotension, tachycardia, sleep disturbances, etc) generally last for 2-10 days. Seizures or hallucinations are rare, even in patients who are barbiturate abusers. The withdrawal phase is shorter in subjects who excessively use triptans [141].

Certain studies have demonstrated that simple information and advice may be enough to achieve headache improvement in many $\mathrm{MOH}$ patients $[142,143]$. In the Brief Intervention for Medication-Overuse Headache (BIMOH) study, a sample of $\mathrm{MOH}$ patients received a brief intervention of education on medication overuse from their GPs. After 3 months, headache and medication days were reduced by 7.3 days/month, and chronic headache resolved in $50 \%$ of the cases [129]. The effectiveness of this brief intervention was confirmed at 6 month-follow up: headache and medication days were reduced by 5.9 days/month, and chronic headache resolved in 63\% [144].

Deciding on the setting for withdrawal is a key point of $\mathrm{MOH}$ treatment. The choice between outpatient and inpatient withdrawal has to consider many factors, including the patient's motivation, the duration of the overuse, the type of overused drugs, possible previous detoxification failures and comorbidities. An outpatient detoxification can be the preferred setting for highly motivated patients, with a short duration of overuse of simple analgesics, and whose everyday life make an inpatient withdrawal unsuitable [145]. Instead, inpatient withdrawal therapy is recommended for patients overusing more complex analgesics (such as opioids, tranquilizers, or barbiturates), long duration of overuse, previous failure to withdraw drugs as outpatients and in more complex clinical situations (e.g. psychiatric comorbidities) [137]. No standardized therapeutic protocol for medication withdrawal is accepted worldwide. Different strategies are employed in clinics such as intravenous hydration, rescue medications such as IV aspirin and IV dihydroergotamine, symptomatic drugs other than those overused, and drugs for withdrawal symptoms including antiemetics (e.g. metoclopramide), clonidine, benzodiazepines, and corticosteroids [36, 146150]. Considering corticosteroids, there is low evidence 
for change in various headache outcome measures (i.e. use of rescue medication, days with severe or moderate headache, days without headache, headache days, and headache frequency) [151, 152]. Evidence in favor of inpatient withdrawal comes from an observational study showing statistically significant improvement of quality of life, depression and anxiety at 6-month follow-up [153]. Furthermore, it is recognized that a proper therapeutic approach to $\mathrm{MOH}$ requires a multistep and multidisciplinary program $[154,155]$. The "COMOESTAS" consortium provided an expert consensus protocol in four centers from Europe and two centers in Latin American. The results show that after multiphasic and personalized treatment, two thirds of patients were no longer overusers and almost half reverted to an episodic headache syndrome over a six-month period [156].

\section{Prophylaxis}

The initiation of preventative therapy is a fundamental therapeutic step to prevent episodic headache converting into a chronic condition. However, the question remains unresolved whether starting prophylactic treatment at the beginning of withdrawal or awaiting the effect of detoxification is the most effective approach. Certain authors recommend that in non-complicated $\mathrm{MOH}$ patients, the decision to start preventive treatment may be postponed for two to 3 months following withdrawal. On the contrary, patients who already have a high frequency of headaches before medication overuse and who have been previously treated with more than one preventive treatment, might need early prophylaxis [157]. Other clinicians believe that the detoxification can be effective without an immediate prophylaxis [126]. To date, as confirmed in a recent meta-analysis of randomized controlled trials on the effect of prophylactic therapies (i.e. valproate, nabilone, onabotulinumtoxinA, topiramate, amitriptyline), there is not a preventative drug that has demonstrated superiority to other therapies in a qualitative, appropriately designed study [152]. The results of randomized controlled trials with patients affected by chronic migraine and $\mathrm{MOH}$ suggest the use of onabotulinumtoxinA and topiramate without early discontinuation. However, the quality of the data is limited due to the fact that it is based on post hoc analysis [158]. A future role for monoclonal antibodies targeting the CGRP pathway is to be awaited [159]. Ultimately, the identification of proper prophylaxis should be driven by clinical history, comorbidity, contraindications and side effects of the possible drugs [126].

\section{Treatment of comorbidities}

Comorbidities have important implications for the management of $\mathrm{MOH}$ in daily clinical practice. Co-existence of mood disorders may lead to poorer adherence of headache treatment, leading to unsuccessful headache treatment.
Comorbid psychiatric disorders add to overall burden and reduced quality of life in headache patients and may lead to poorer outcomes after treatment. Therefore, screening patients for anxiety and depression, is important for clinical outcomes and for trials studying MOH. Lastly, attention for metabolic disturbances or unhealthy lifestyle behavioural aspects, such as obesity, smoking and inactivity, in daily practice is probably beneficial not only for general health but also for headache outcomes. As these are mostly modifiable factors, it is reasonable to discuss and treat these conditions accordingly.

\section{Prognosis}

In general, overuse of acute treatment can lead to a poor prognosis of chronic headache and lower quality of life by itself [160]. The outcome for $\mathrm{MOH}$ patients withdrawing from their acute treatments has been reported in multiple studies. An accepted endpoint for good response to therapy is a $\geq 50 \%$ reduction from baseline headache frequency and/or headache index [161]. Successful withdrawal has been found in around $50-70 \%$ of $\mathrm{MOH}$ patients after 1 year [68, 162-170]. Retaining full withdrawal after 1 year was found to be a good predictor for long-term success [171, 172]. In studies with long-term evaluations up to 6 years, relapsing rates between 40 and 50\% were found [163, 164, 173-177]. A successful withdrawal leads to a better response for prophylactic treatment, even in patients with little improvement in headache frequency [178]. Multiple predictors of relapse have been documented. Patients with tension-type headache have a higher relapse risk [162$164,173,179]$. A longer duration of regular intake is a predictor for relapse [174, 180]. Patients who kept overusing medication in the long-term had a poor response to withdrawal therapy and had a higher frequency of chronic headache [171]. Risk factors for relapse in short-term (1 year) were: high number of acute treatments, smoking, alcohol consumption and return to overused drugs [181]. Patients withdrawn from triptans have a lower risk for relapse, while combined drug therapy had a higher relapse rate $[163,179,182]$. Codeine containing drugs, low self-reported sleep quality and high self-reported bodily pain are probable predictors for poor outcome after 1 yr [170].

\section{Debates in $\mathrm{MOH}$}

The idea of $\mathrm{MOH}$ is well-known and widespread in clinics worldwide. By using the operational criteria for $\mathrm{MOH}$ in the ICHD-3 classification, clinicians are able to diagnose $\mathrm{MOH}$ as early as first clinic visits in order to guide patients in cutting down the amount of frequently used analgesics.

The evidence in favor of the disorder $\mathrm{MOH}$ is substantial since global research has gradually improved our 
knowledge on the complexity of the disorder. Consistent observations from population-based longitudinal studies by headache experts in expertise centers worldwide, have established the entity of $\mathrm{MOH}$ in a considerable amount of headache patients. Research on the pathophysiological mechanisms is steadily unravelling the different processes involved with analgesic overuse in headache syndromes. Agreement in findings from imaging studies for entity-specific alterations in the brain have been published, although the amount of data is still limited and needs further research [86, 87]. Furthermore, the results from neuroimaging suggest that neuroplasticity exists and that specific imaging findings can be predictive for the outcome after withdrawal. Lastly, the field of genetics in $\mathrm{MOH}$ is in development, reaching out to a more personalized approach for $\mathrm{MOH}$ [159].

However, it is important to raise awareness on the current limitations to the state of literature on $\mathrm{MOH}$. Questions need to be put forward on how to analyse the phenomenon of deteriorating headaches with the use of analgesics. Mostly, the disorder is seen in patients with pre-existing headache disorders and therefore analysing it as a complication to these conditions is reasonable. Given the potential for the onset of chronic headache after regular intake of analgesics for other medical conditions, $\mathrm{MOH}$ can be conceptualized as a secondary headache disorder. But reminding ourselves to patients who experience increasing headache severity and frequency without drug overuse, the overuse of analgesics can be seen as a mere epiphenomenon to the primary headache disorder, a cycling disorder with good and bad phases, for which treatment of the headache syndrome without detoxification is required $[155,183]$. The scientific community has not yet come to the end of this discussion. The lack of robust evidence from high-quality, well-designed and large randomized controlled clinical trials on $\mathrm{MOH}$ is important in this analysis [184]. Withdrawal studies over the years have delivered evidence of moderate quality, mostly due to the lack of control groups, lack of randomization, difficulties in adequate blinding and often high dropout rates [158, 184]. Furthermore, evidence in favour of starting prophylactic treatment in $\mathrm{MOH}$ comes from post-hoc analysis without adequate power [134, 158]. One of the most critical aspects of $\mathrm{MOH}$ treatment concerns discontinuation of the symptomatic medication. This concept is installed by using observational data and specialist consensus, not on solid level of evidence from large and well powered randomized, blinded trials [137, 139]. Because of the huge burden of disease for patients, larger and high-quality interventional trials on the efficacy of treatments are needed $[158,184]$. This is complicated by a significant limitation. For an individual patient, the existence of $\mathrm{MOH}$ can neither be proven nor invalidated due to the lack of pathognomonic clinical aspects or a clinical useful biomarker, and therefore studies will still rely on consensus criteria.

The diagnostic criteria for $\mathrm{MOH}$ in the international classification remain fuel for debate, even after three editions and multiple decades. The discussion whether $\mathrm{MOH}$ has a rightful place in the classification as a secondary headache disorder is interesting and relevant. The current ICHD-3 criteria do not denominate $\mathrm{MOH}$ to be a 'transformed' version of a primary headache disorder, but instead describe a concurrent medical problem occurring with an underlying headache disorder. The diagnosis is neither a definitive claim on the cause of a progressive headache disorder either. It has a more moderate approach to the occurrence of medication overuse than previous clinical criteria. Furthermore, the current classification uses clinical features that do not touch upon on the underlying neurobiological processes and has rigid elements such as the cut-off of 15 days per month. These elements may need to be revisited when new evidence becomes available in the future [23].

Finally, different authors discussed the previous, current and possible future terminology used in the field of MOH. In terms of semantics, the term "medication-overuse headache" was challenged by Solomon et al. in 2011 [185]. MOH has a potential stigmatizing and (self-) blaming message to patients that can put pressure on a good patient-physician relationship. Appellations as "iatrogenic headache" and "medication-overtreatment headache" have a potential to lay blame on healthcare providers [184]. On the other hand, terminology such as "medication misuse headache", "medication abuse headache", "drug abuse headache" also carry a clue of leaving patients responsible for the development of the situation. Hence Solomon et al analyzed possible mechanism-based definitions, for instance "medication-induced headache", "feed-forward headache", "drug-transformed (or amplified) headache" and suggested implicating the term "medication-adaptation headache" as the most appropriate [185].

To summarize, after analyzing the literature on $\mathrm{MOH}$, it is our understanding that for clinicians in daily practice, the evaluation of the frequency and quantity of use of analgesics in patients with headache syndromes is a key component of medical assessment in headache disorders. Side effects of analgesic overuse must be actively evaluated and treated accordingly. However, $\mathrm{MOH}$ is not to be diagnosed rapidly without further intellectual perseverance, since a false-positive diagnosis of $\mathrm{MOH}$ can lead to misdiagnosis. Other secondary causes of headache may lead to headache progression in conjunction with medication overuse. We therefore state that a critical appraisal of the entity of $\mathrm{MOH}$ is required in 
every individual patient. A thorough clinical approach with exact history taking to detect temporal relationships, and clinical examination focused on neurological deficits, remain the foremost necessary assets for clinicians in the absence of accurate technical tools.

\section{Conclusion}

Research in $\mathrm{MOH}$ is moving forward and is discovering the mechanisms underlying headache progression and medication overuse. Whether $\mathrm{MOH}$ is a definitive distinct entity, a complication in the pathophysiology of primary headache disorders or an epiphenomenon in the natural course of headache disorders is still up for debate. Since methodology is improving and world-wide collaborative efforts are being established, it is clear that high-quality research will help us to resolve multiple questions stated above. Ultimately, by making scientific progress, we are hopeful that new evidence will help clinicians to make the right choices for patients suffering highly disabling headaches and comorbidities.

\begin{abstract}
Abbreviations
5HT-2A: Serotonin 2A; BIMOH: Brief Intervention for Medication-Overuse Headache; CGRP: Calcitonin-gene related peptide; CM: Chronic migraine; CSD: Cortical spreading depression; CTTH: Chronic tension-type headache; EM: Episodic migraine; FDG-PET: [18F] fluorodeoxyglucose-Positron emission tomography; GBD: Global Burden of Disease; GP: General practitioner; HADS: Hospital Anxiety and Depression Scale; ICHD: International Classification of Headache Disorders; ICHD-2: Second Edition of the International Classification of Headache Disorders; ICHD-3: Third Edition of the International Classification of Headache Disorders; $\mathrm{MOH}$ : Medication-overuse headache; NSAID: Non-steroidal anti-inflammatory drug; OCD: Obsessive-compulsive disorder; OFC: Orbitofrontal cortex; OR: Odds ratio; PAG: Periaqueductal gray; RR: Relative risk; SAMOHA: Sodium Valproate in Medication Overuse Headache Treatment; VMPFC: Ventromedial prefrontal cortex
\end{abstract}

\section{Acknowledgements}

The European Headache Federation and the Department of Clinical and Molecular Medicine, Sapienza University of Rome, are gratefully acknowledged for supporting this work.

\section{Funding}

This work was supported and funded by the European Headache Federation - School of Advanced Studies.

\section{Authors' contributions}

KP and ZK conceived the review. All authors designed the review, drafted the manuscript and revised it for intellectual content. All authors read and approved the final manuscript.

\section{Authors' information}

Nicolas Vandenbussche, Domenico Laterza, Marco Lisicki, Joseph Lloyd, Chiara Lupi, Hannes Tischler, Kati Toom, Fenne Vandervorst and Simone Quintana are Junior Fellows of EHF-SAS.

Koen Paemeleire and Zaza Katsarava are Senior Fellows of EHF-SAS.

Ethics approval and consent to participate

Not applicable.

\section{Consent for publication}

Not applicable.

\section{Competing interests}

NV has received travel and educational grants from Allergan.
KP has received personal compensation from Allergan, Almirall, Amgen/ Novartis, Autonomic Technologies Inc., Coherex, Janssen-Cilag, Lilly, Medtronic, Pfizer, Sandoz, Sanofi, St Jude Medical and Teva for consulting, serving on a scientific advisory board and/or speaking. ZK has received honoraria from Novartis, Allergan, MSD, Lilly, TEVA.

\section{Publisher's Note}

Springer Nature remains neutral with regard to jurisdictional claims in published maps and institutional affiliations.

\section{Author details}

${ }^{1}$ Headache Group, Department of Basic and Clinical Neuroscience, King's College London, and NIHR-Wellcome Trust King's Clinical Research Facility, King's College Hospital, Denmark Hill, London SE5 9PJ, UK. Department of Neuroscience, St. Agostino Estense Hospital, University of Modena and Reggio Emilia, via P. Giardini 1355, 41100 Modena, Italy. ${ }^{3}$ Headache Research Unit, Université de Liège, Liège, Belgium. ${ }^{4}$ Headache Research-Wolfson CARD, King's College London, London, UK. ${ }^{5}$ Headache Centre, Careggi University Hospital, Health Sciences Department, University of Florence, Viale Pieraccini 6, 50139 Florence, Italy. ${ }^{6}$ Department of Neurology, Medical University Innsbruck, Innsbruck, Austria. ${ }^{7}$ Department of Neurology, Tartu University Clinics, Tartu, Estonia. ${ }^{8}$ Estonian Headache Society, Tartu, Estonia.

${ }^{9}$ Department Neurology, UZ Brussel, Jette, Belgium. ${ }^{10}$ Headache Center, Department of Medicine and Surgery, University of Parma, Parma, Italy.

${ }^{11}$ Department of Neurology, Ghent University Hospital, Corneel Heymanslaan 10, B-9000 Ghent, Belgium. ${ }^{12}$ Evangelical Hospital Unna and University of Duisburg-Essen, Duisburg, Germany.

Received: 15 April 2018 Accepted: 13 June 2018

Published online: 13 July 2018

\section{References}

1. Diener HC, Holle D, Solbach K, Gaul C (2016) Medication-overuse headache: risk factors, pathophysiology and management. Nat Rev Neurol 12:575-583. https://doi.org/10.1038/nrneurol.2016.124

2. Evers S, Marziniak M (2010) Clinical features, pathophysiology, and treatment of medication-overuse headache. Lancet Neurol 9:391-401. https://doi.org/10.1016/S1474-4422(10)70008-9

3. Boes CJ, Capobianco DJ (2005) Chronic migraine and medication-overuse headache through the ages. Cephalalgia 25:378-390. https://doi.org/10. 1111/j.1468-2982.2005.00868.x

4. Lennox W (1934) The use of ergotamine tartrate in migraine. N Engl J Med 210:1061-1065

5. Silfverskiöld B (1947) Gynergen abuse in cases of migraine. Acta Psychi Search results. Acta Psychiatr Neurol 46:281-285

6. Graham JR (1955) Treatment of migraine. N Engl J Med 253:726-730; contd. https://doi.org/10.1056/NEJM195510272531705

7. Lippman CW (1955) Characteristic headache resulting from prolonged use of ergot derivatives. J Nerv Ment Dis 121:270-273

8. Friedman AP, Von Storch TJ (1955) Ergotamine tolerance in patients with migraine. J Am Med Assoc 157:881-884

9. Peters GA, Horton BT (1951) Headache: with special reference to the excessive use of ergotamine preparations and withdrawal effects. Proc Staff Meet Mayo Clin 26:153-161

10. Horton B, Peters G (1963) Clinical manifestations of excessive use of ergotamine preparations and Management of Withdrawal Effect: report of 52 cases. Headache J Head Face Pain 2:214-229. https://doi.org/10.1111/j. 1526-4610.1963.hed0204214.x

11. Wörz R, Baar H, Draf W et al (1975) Headache and dependence on mixed analgesic preparations. MMW Munch Med Wochenschr 117:457-462

12. Worz R (1980) Abuse and paradoxical effects of analgesic drug mixtures. $\mathrm{Br}$ J Clin Pharmacol 10:391S-393S. https://doi.org/10.1111/j.1365-2125.1980. tb01828.x

13. Mathew NT, Stubits E, Nigam MP (1982) Transformation of episodic migraine into daily headache: analysis of factors. Headache J Head Face Pain 22:66-68. https://doi.org/10.1111/j.1526-4610.1982.hed2202066.x

14. Mathew NT, Reuveni U, Perez F (1987) Transformed or Evolutive migraine. Headache J Head Face Pain 27:102-106. https://doi.org/10.1111/j.1526-4610. 1987.hed2702102.x

15. Headache Classification Committee of the International Headache Society (1988) Classification and diagnostic criteria for headache disorders, cranial 
neuralgias and facial pain. Headache classification Committee of the International Headache Society. Cephalalgia 8(Suppl 7):1-96

16. Kaube H, May A, Pfaffenrath V (1994) Sumatriptan. BMJ 308:1573-1574

17. Limmroth V, Kazarawa Z, Fritsche G, Diener HC (1999) Headache after frequent use of serotonin agonists zolmitriptan and naratriptan. Lancet 353: 378. https://doi.org/10.1016/S0140-6736(05)74950-3

18. Limmroth V, Katsarava Z, Fritsche G et al (2002) Features of medication overuse headache following overuse of different acute headache drugs. Neurology 59:1011-1014. https://doi.org/10.1212/WNL.59.7.1011

19. Silberstein SD, Lipton RB, Solomon S, Mathew NT (1994) Classification of daily and near-daily headaches: proposed revisions to the IHS criteria. Headache 34:1-7

20. Headache Classification Subcommittee of the International Headache Society (2004) The international classification of headache disorders: 2nd edition. Cephalalgia 24(Suppl 1):9-160

21. Olesen J, Bousser MG, Diener HC et al (2006) New appendix criteria open for a broader concept of chronic migraine. Cephalalgia 26:742-746. https:// doi.org/10.1111/j.1468-2982.2006.01172.x

22. Headache Classification Committee of the International Headache Society (2018) Headache classification Committee of the International Headache Society (IHS) the international classification of headache disorders, 3rd edition. Cephalalgia 38:1-211. https://doi.org/10.1177/ 0333102417738202

23. Manzoni G, Torelli P (2015) Chronic headaches: a clinician's experience of ICHD3 beta. Neurol Sci 36:51-55. https://doi.org/10.1007/s10072

24. Tepper S (2012) Medication-overuse headache (MOH). Contin Lifelong Learn Neurol 18:807-822. https://doi.org/10.1007/978-3-319-19911-5_19

25. Scher Al, Lipton RB, Stewart WF, Bigal M (2010) Patterns of medication use by chronic and episodic headache sufferers in the general population: results from the frequent headache epidemiology study. Cephalalgia 30: 321-328. https://doi.org/10.1111/j.1468-2982.2009.01913.x

26. Bigal ME, Lipton RB (2008) Excessive acute migraine medication use and migraine progression. Neurology 71:1821-1828. https://doi.org/10.1212/01. wnl.0000335946.53860.1d

27. Katsarava Z, Schneeweiss S, Kurth T et al (2004) Incidence and predictors for chronicity of headache in patients with episodic migraine. Neurology 62: 788-790. https://doi.org/10.1212/01.WNL.0000113747.18760.D2

28. Westergaard ML, Hansen EH, Glümer C et al (2014) Definitions of medication-overuse headache in population-based studies and their implications on prevalence estimates: a systematic review. Cephalalgia 34: 409-425. https://doi.org/10.1177/0333102413512033

29. Ayzenberg I, Katsarava Z, Sborowski A et al (2012) The prevalence of primary headache disorders in Russia: a countrywide survey. Cephalalgia 32: 373-381. https://doi.org/10.1177/0333102412438977

30. Park J-W, Moon H-S, Kim J-M et al (2014) Chronic daily headache in Korea: prevalence, clinical characteristics, medical consultation and management. J Clin Neurol 10:236. https://doi.org/10.3988/jcn.2014.10.3.236

31. Yu S, Liu R, Zhao G et al (2012) The prevalence and burden of primary headaches in China: a population-based door-to-door survey. Headache 52: 582-591. https://doi.org/10.1111/j.1526-4610.2011.02061.x

32. Zebenigus M, Tekle-Haimanot R, Worku DK et al (2016) The prevalence of primary headache disorders in Ethiopia. J Headache Pain 17:110. https://doi. org/10.1186/s10194-016-0704-Z

33. Mbewe E, Zairemthiama P, Yeh H-H et al (2015) The epidemiology of primary headache disorders in Zambia: a population-based door-to-door survey. J Headache Pain 16:515. https://doi.org/10.1186/s10194-015-0515-7

34. Da Silva A, Costa EC, Gomes JB et al (2010) Chronic headache and comorbibities: a two-phase, population-based, cross-sectional study. Headache 50:1306-1312. https://doi.org/10.1111/j.1526-4610.2010.01620.x

35. Westergaard ML, Munksgaard SB, Bendtsen L, Jensen RH (2016) Medicationoveruse headache: a perspective review. Ther Adv Drug Saf 7:147-158. https://doi.org/10.1177/2042098616653390

36. Kristoffersen ES, Lundqvist C (2014) Medication-overuse headache: epidemiology, diagnosis and treatment. Ther Adv Drug Saf 5:87-99. https:// doi.org/10.1177/2042098614522683

37. Global Burden of Disease Study 2013 Collaborators (2015) Global, regional, and national incidence, prevalence, and years lived with disability for 301 acute and chronic diseases and injuries in 188 countries, 1990?2013: a systematic analysis for the Global Burden of Disease Study 2013. Lancet 386:743-800. https://doi. org/10.1016/S0140

38. Cheung V, Amoozegar F, Dilli E (2015) Medication overuse headache. Curr Neurol Neurosci Rep 15:509. https://doi.org/10.1007/s11910-014-0509-x
39. Munksgaard SB, Jensen RH (2014) Medication overuse headache. Headache 54:1251-1257. https://doi.org/10.1111/head.12408

40. Irimia P, Palma JA, Fernandez-Torron R, Martinez-Vila E (2011) Refractory migraine in a headache clinic population. BMC Neurol 11(1):94. https://doi. org/10.1186/1471-2377-11-94

41. Wang S-J, Fuh J-L, Liu C-Y et al (2000) Chronic daily headache in Chinese elderly: prevalence, risk factors, and biannual follow-up. Neurology 54:314319. https://doi.org/10.1212/WNL.54.2.314

42. Straube A, Pfaffenrath V, Ladwig KH et al (2010) Prevalence of chronic migraine and medication overuse headache in Germany - the German DMKG headache study. Cephalalgia 30:207-213. https://doi.org/10.1111/j. 1468-2982.2009.01906.x

43. Jonsson P, Hedenrud T, Linde M (2011) Epidemiology of medication overuse headache in the general Swedish population. Cephalalgia 31:10151022. https://doi.org/10.1177/0333102411410082

44. Gelfand AA, Goadsby PJ (2014) Medication overuse in children and adolescents. Curr Pain Headache Rep 18:428. https://doi.org/10.1016/j. neuron.2009.10.017.A

45. Lipton RB, Manack A, Ricci JA et al (2011) Prevalence and burden of chronic migraine in adolescents: results of the chronic daily headache in adolescents study (C-dAS). Headache 51:693-706. https://doi.org/10.1111/j. 1526-4610.2011.01885.x

46. Wiendels NJ, van der Geest MCM, Neven MSAK et al (2005) Chronic daily headache in children and adolescents. Headache J Head Face Pain 45:678683. https://doi.org/10.1111/j.1526-4610.2005.05137.x

47. Maffioletti E, Ferro F, Pucci E et al (2015) P035. Headache prevalence and disability among Italian adolescents aged 11-15 years: a population crosssectional study. J Headache Pain 16:A148. https://doi.org/10.1186/11292377-16-S1-A148

48. Wang S-J, Fuh J-L, Lu S-R, Juang K-D (2006) Chronic daily headache in adolescents. Neurology 66:193-197. https://doi.org/10.1212/WNL. 0b013e3181d2b185

49. Krogh AB, Larsson B, Linde M (2015) Prevalence and disability of headache among Norwegian adolescents: a cross-sectional school-based study. Cephalalgia 35:1181-1191. https://doi.org/10.1177/0333102415573512

50. Moore AJ, Shevell M (2004) Chronic daily headaches in pediatric neurology practice. J Child Neurol 19:925-929

51. Prencipe $M$, Casini AR, Ferretti $C$ et al (2001) Prevalence of headache in an elderly population: attack frequency, disability, and use of medication. J Neurol Neurosurg Psychiatry 70:377-381. https://doi.org/10.1136/jnnp.70.3.377

52. de Rijk P, Resseguier N, Donnet A (2017) Headache characteristics and clinical features of elderly migraine patients. Headache J Head Face Pain 58(4):525-533. https://doi.org/10.1111/head.13247

53. Westergaard ML, Glumer C, Hansen EH, Jensen RH (2014) Prevalence of chronic headache with and without medication overuse: associations with socioeconomic position and physical and mental health status. Pain 155: 2005-2013. https://doi.org/10.1016/j.pain.2014.07.002

54. Linde M, Gustavsson A, Stovner LJ et al (2012) The cost of headache disorders in Europe: the Eurolight project. Eur J Neurol 19:703-711. https:// doi.org/10.1111/j.1468-1331.2011.03612.x

55. Steiner TJ (2005) Lifting the burden: the global campaign to reduce the burden of headache worldwide. J Headache Pain 6:373-377. https://doi.org/ 10.1007/s10194-005-0241-7

56. Steiner TJ, Stovner LJ, Katsarava $Z$ et al (2014) The impact of headache in Europe: principal results of the Eurolight project. J Headache Pain 15:1-11. https://doi.org/10.1186/1129-2377-15-31

57. Vos T, Abajobir AA, Abate KH et al (2017) Global, regional, and national incidence, prevalence, and years lived with disability for 328 diseases and injuries for 195 countries, 1990-2016: a systematic analysis for the global burden of disease study 2016. Lancet 390:1211-1259. https://doi.org/10. 1016/S0140-6736(17)32154-2

58. Ashina S, Lyngberg A, Jensen RH (2010) Headache characteristics and chronification of migraine and tension-type headache: a population-based study. Cephalalgia 30:943-954. https://doi.org/10.1177/0333102409357958

59. Thorlund K, Sun-Edelstein C, Druyts E et al (2016) Risk of medication overuse headache across classes of treatments for acute migraine. $J$ Headache Pain 17(1):107. https://doi.org/10.1186/s10194-016-0696-8

60. Bigal ME, Serrano D, Buse D et al (2008) Acute migraine medications and evolution from episodic to chronic migraine: a longitudinal populationbased study. Headache 48:1157-1168. https://doi.org/10.1111/j.1526-4610. 2008.01217.x 
61. Paemeleire K, Bahra A, Evers S et al (2006) Medication-overuse headache in patients with cluster headache. Neurology 67:109-113. https://doi.org/10. 1111/j.1468-2982.2008.01736.x

62. Paemeleire K, Evers S, Goadsby PJ (2008) Medication overuse headache in patients with cluster headache. Curr Pain Headache Rep 12:122-127

63. Wilkinson SM, Becker WJ, Heine JA (2001) Opiate use to control bowel motility may induce chronic daily headache in patients with migraine. Headache 41:303-309. https://doi.org/10.1046/j.1526-4610.2001.111006303.x

64. Bahra A, Walsh M, Menon S, Goadsby PJ (2003) Does chronic daily headache arise de novo in association with regular use of analgesics? Headache 43:179-190. https://doi.org/10.1046/j.1526-4610.2003.03041.x

65. Hagen K, Albretsen C, Vilming ST et al (2011) A 4-year follow-up of patients with medication-overuse headache previously included in a randomized multicentre study. J Headache Pain 12:315-322. https://doi.org/10.1007/s10194-010-0285-1

66. Cevoli S, Sancisi E, Grimaldi D et al (2009) Family history for chronic headache and drug overuse as a risk factor for headache chronification. Headache 49:412-418. https://doi.org/10.1111/j.1526-4610.2008.01257.x

67. Bigal ME, Lipton RB (2007) The differential diagnosis of chronic daily headaches: an algorithm-based approach. J Headache Pain 8:263-272. https://doi.org/10.1007/s10194-007-0418-3

68. Baumgartner C, Wessely P, Bingöl C et al (1989) Longterm prognosis of analgesic withdrawal in patients with drug-induced headaches. Headache 29:510-514. https://doi.org/10.1111/j.1526-4610.1989.hed2908510.x

69. Hagen K, Linde M, Steiner TJ et al (2012) Risk factors for medication-overuse headache: an 11-year follow-up study. The Nord-Trøndelag health studies. Pain 153:56-61. https://doi.org/10.1016/j.pain.2011.08.018

70. Ashina S, Serrano D, Lipton RB et al (2012) Depression and risk of transformation of episodic to chronic migraine. J Headache Pain 13:615624. https://doi.org/10.1007/s10194-012-0479-9

71. Sarchielli P, Corbelli I, Messina P et al (2016) Psychopathological comorbidities in medication-overuse headache: a multicentre clinical study. Eur J Neurol 23:85-91. https://doi.org/10.1111/ene.12794

72. Kristoffersen ES, Straand J, Russell MB, Lundqvist C (2016) Disability, anxiety and depression in patients with medication-overuse headache in primary care - the BIMOH study. Eur J Neurol 23:28-35. https://doi.org/10.1111/ene.12850

73. Bendtsen L, Munksgaard SB, Tassorelli C et al (2014) Disability, anxiety and depression associated with medication-overuse headache can be considerably reduced by detoxification and prophylactic treatment. Results from a multicentre, multinational study (COMOESTAS project). Cephalalgia 34:426-433. https://doi.org/10.1177/0333102413515338

74. Lampl C, Thomas H, Tassorelli C et al (2016) Headache, depression and anxiety: associations in the Eurolight project. J Headache Pain 17(1):59. https://doi.org/10.1186/s10194-016-0649-2

75. Curone M, Tullo V, Mea E et al (2011) Psychopathological profile of patients with chronic migraine and medication overuse : study and findings in 50 cases. Neurol Sci 32:177-179. https://doi.org/10.1007/s10072-011-0527-2

76. Cupini LM, Murtas MD, Costa C et al (2009) Obsessive-compulsive disorder and migraine with medication-overuse headache: research submission. Headache 49:1005-1013. https://doi.org/10.1111/j.1526-4610.2009.01457.x

77. Radat F, Lanteri-Minet M (2010) What is the role of dependence-related behavior in medication-overuse headache? Headache 50:1597-1611. https:// doi.org/10.1111/j.1526-4610.2010.01755.x

78. Galli F, Pozzi G, Frustaci A et al (2011) Differences in the personality profile of medication-overuse headache sufferers and drug addict patients: a comparative study using MMPI-2. Headache 51:1212-1227. https://doi.org/ 10.1111/j.1526-4610.2011.01978.x

79. Scher Al, Stewart WF, Ricci JA, Lipton RB (2003) Factors associated with the onset and remission of chronic daily headache in a population-based study. Pain 106:81-89. https://doi.org/10.1016/S0304-3959(03)00293-8

80. Bigal ME, Liberman JN, Lipton RB (2006) Obesity and migraine: a population study. Neurology 66:545-550. https://doi.org/10.1212/01.wnl.0000197218.05284.82

81. He Z, Dong L, Zhang Y et al (2015) Metabolic syndrome in female migraine patients is associated with medication overuse headache: a clinic-based study in China. Eur J Neurol 22:1228-1234. https://doi.org/10.1111/ene.12732

82. Westergaard ML, Glümer C, Hansen EH, Jensen RH (2016) Medication overuse, healthy lifestyle behaviour and stress in chronic headache: results from a population-based representative survey. Cephalalgia 36:15-28. https://doi.org/10.1177/0333102415578430

83. Hershey AD, Powers SW, Nelson TD et al (2009) Obesity in the pediatric headache population: a multicenter study. Headache J Head Face Pain 49: 170-177. https://doi.org/10.1111/j.1526-4610.2008.01232.x
84. Pakalnis A, Kring D (2012) Chronic daily headache, medication overuse, and obesity in children and adolescents. J Child Neurol 27:577-580. https://doi. org/10.1177/0883073811420869

85. Sancisi E, Cevoli S, Vignatelli L et al (2010) Increased prevalence of sleep disorders in chronic headache: a case-control study. Headache 50:14641472. https://doi.org/10.1111/j.1526-4610.2010.01711.x

86. Srikiatkhachorn A, le Grand SM, Supornsilpchai W, Storer RJ (2014) Pathophysiology of medication overuse headache-an update. Headache J Head Face Pain 54:204-210. https://doi.org/10.1111/head.12224

87. Schwedt TJ, Chong CD (2017) Medication overuse headache: pathophysiological insights from structural and functional brain MRI research. Headache J Head Face Pain 57(7):1173-1178. https://oi.org/10.1111/head.13037

88. Lai T, Wang S (2018) Neuroimaging findings in patients with medication overuse headache. Curr Pain Headache Rep 22:1. https://doi.org/10.1007/ s11916-018-0661-0

89. Supornsilpchai W, Maneesri Le Grand S, Srikiatkhachorn A (2010) Cortical hyperexcitability and mechanism of medication-overuse headache. Cephalalgia 30:1101-1109. https://doi.org/10.1177/0333102409355600

90. Green A, Gu P, De Felice M et al (2014) Increased susceptibility to cortical spreading depression in an animal model of medication-overuse headache. Cephalalgia 34:594-604. https://doi.org/10.1016/..smim.2015.08.001.Control

91. Bongsebandhu-Phubhakdi S, Srikiatkhachorn A (2012) Pathophysiology of medication-overuse headache: implications from animal studies. Curr Pain Headache Rep 16:110-115. https://doi.org/10.1007/s11916-011-0234-y

92. Belanger S, Ma W, Chabot J-G, Quirion R (2002) Expression of calcitonin gene-related peptide, substance $P$ and protein kinase $C$ in cultured dorsal root ganglion neurons following chronic exposure to mu, delta and kappa opiates. Neuroscience 115:441-453. https://doi.org/10.1016/S03064522(02)00452-9

93. De Felice M, Ossipov MH, Wang R et al (2010) Triptan-induced enhancement of neuronal nitric oxide synthase in trigeminal ganglion dural afferents underlies increased responsiveness to potential migraine triggers. Brain 133:2475-2488. https://doi.org/10.1093/brain/awq159

94. Okada-Ogawa A, Porreca F, Meng ID (2009) Sustained morphine-induced sensitization and loss of diffuse noxious inhibitory controls (DNIC) in durasensitive medullary dorsal horn neurons. J Neurosci 29:15828-15835. https:// doi.org/10.3174/ajnr.A1256.Functional

95. Wanasuntronwong A, Jansri U, Srikiatkhachorn A (2017) Neural hyperactivity in the amygdala induced by chronic treatment of rats with analgesics may elucidate the mechanisms underlying psychiatric comorbidities associated with medication-overuse headache. BMC Neurosci 18:1-12. https://doi.org/ 10.1186/s12868-016-0326-z

96. Srikiatkhachorn A, Tarasub N, Govitrapong P (2000) Effect of chronic analgesic exposure on the central serotonin system: a possible mechanism of analgesic abuse headache. Headache 40:343-350. https://doi.org/10. 1046/j.1526-4610.2000.00052.x

97. Tohyama Y, Yamane F, Merid MF, Diksic M (2001) Effects of selective 5-HT1A receptor antagonists on regional serotonin synthesis in the rat brain: an autoradiographic study with alpha-[14C] methyl-L-tryptophan. Eur Neuropsychopharmacol 11:193-202

98. Dobson CF, Tohyama Y, Diksic M, Hamel E (2004) Effects of acute or chronic administration of anti-migraine drugs sumatriptan and zolmitriptan on serotonin synthesis in the rat brain. Cephalalgia 24:2-11. https://doi.org/10. 1111/j.1468-2982.2004.00647.x

99. Srikiatkhachorn A, Anthony M (1996) Platelet serotonin in patients with analgesic-induced headache. Cephalalgia 16:423-426. https://doi.org/10 1046/j.1468-2982.1996.1606423.x

100. Cargnin S, Viana M, Sances G et al (2017) A systematic review and critical appraisal of gene polymorphism association studies in medication-overuse headache. Cephalalgia 0:1-13. https://doi.org/10.1177/0333102417728244

101. Pisanu C, Caproni S, Congiu D et al (2015) HDAC3 role in medication consumption in medication overuse headache patients: a pilot study. Hum Genomics 9:30. https://doi.org/10.1186/s40246-015-0051-1

102. Terrazzino S, Sances G, Balsamo F et al (2010) Role of 2 common variants of 5HT2A gene in medication overuse headache. Headache 50:1587-1596. https://doi.org/10.1111/j.1526-4610.2010.01757.x

103. Di Lorenzo C, Sances G, Di Lorenzo G et al (2007) The wolframin His611Arg polymorphism influences medication overuse headache. Neurosci Lett 424: 179-184. https://doi.org/10.1016/j.neulet.2007.07.037

104. Cargnin S, Viana M, Ghiotto N et al (2014) Functional polymorphisms in COMT and SLC6A4 genes influence the prognosis of patients with 
medication overuse headache after withdrawal therapy. Eur J Neurol 21: 989-995. https://doi.org/10.1111/ene.12424

105. Cevoli S, Mochi M, Scapoli C et al (2006) A genetic association study of dopamine metabolism-related genes and chronic headache with drug abuse. Eur J Neurol 13:1009-1013. https://doi.org/10.1111/j.1468-1331.2006 01415.x

106. Di Lorenzo C, Di Lorenzo G, Sances G et al (2009) Drug consumption in medication overuse headache is influenced by brain-derived neurotrophic factor Val66Met polymorphism. J Headache Pain 10:349-355. https://doi. org/10.1007/s10194-009-0136-0

107. Di Lorenzo C, Coppola G, Currà A et al (2012) Cortical response to somatosensory stimulation in medication overuse headache patients is influenced by angiotensin converting enzyme (ACE) I/D genetic polymorphism. Cephalalgia 32:1189-1197. https://doi.org/10.1177/ 0333102412461890

108. Woolf CJ (2012) Central sensitization: implications for the diagnosis and treatment of pain. Pain 152:1-31. https://doi.org/10.1016/j.pain.2010.09.030 Central

109. Coppola G, Curra A, Di Lorenzo C et al (2010) Abnormal cortical responses to somatosensory stimulation in medication-overuse headache. BMC Neurol 10:126. https://doi.org/10.1186/1471-2377-10-126

110. Curra A, Coppola G, Gorini M et al (2011) Drug-induced changes in cortical inhibition in medication overuse headache. Cephalalgia an Int jounal headache 31:1282-1290. https://doi.org/10.1177/0333102411415877

111. Munksgaard SB, Bendtsen L, Jensen RH (2013) Modulation of central sensitisation by detoxification in $\mathrm{MOH}$ : results of a 12-month detoxification study. Cephalalgia 33:444-453. https://doi.org/10.1177/0333102412475235

112. Riederer F, Marti M, Luechinger R et al (2012) Grey matter changes associated with medication-overuse headache: correlations with disease related disability and anxiety. World J Biol Psychiatry 13:517-525. https://doi. org/10.3109/15622975.2012.665175

113. Michels L, Christidi F, Steiger VR et al (2017) Pain modulation is affected differently in medication-overuse headache and chronic myofascial pain - a multimodal MRI study. Cephalalgia 37:764-779. https://doi.org/10.1177/ 0333102416652625

114. Schmidt-Wilcke T, Leinisch E, Straube A et al (2005) Gray matter decrease in patients with chronic tension type headache. Neurology 65:1483-1486. https://doi.org/10.1212/01.wnl.0000183067.94400.80

115. Chanraud S, Di Scala G, Dilharreguy B et al (2014) Brain functional connectivity and morphology changes in medication-overuse headache: clue for dependence-related processes? Cephalalgia 34:605-615. https://doi. org/10.1177/0333102413519514

116. Ferraro S, Grazzi L, Mandelli ML et al (2012) Pain processing in medication overuse headache: a functional magnetic resonance imaging (FMRI) study. Pain Med 13:255-262. https://doi.org/10.1111/j.1526-4637.2011.01183.x

117. Ferraro S, Grazzi L, Muffatti R et al (2012) In medication-overuse headache, fMRI shows long-lasting dysfunction in midbrain areas. Headache 52:15201534. https://doi.org/10.1111/j.1526-4610.2012.02276.x

118. Torta DM, Costa T, Luda E et al (2016) Nucleus accumbens functional connectivity discriminates medication-overuse headache. Neurolmage Clin 11:686-693. https://doi.org/10.1016/j.nicl.2016.05.007

119. Fumal A, Laureys S, Di Clemente L et al (2006) Orbitofrontal cortex involvement in chronic analgesic-overuse headache evolving from episodic migraine. Brain 129:543-550. https://doi.org/10.1093/brain/awh691

120. Riederer F, Schaer M, Gantenbein AR et al (2017) Cortical alterations in medication-overuse headache. Headache 57:255-265. https://doi.org/10. 1111/head.12993

121. Riederer F, Gantenbein AR, Marti M et al (2013) Decrease of gray matter volume in the midbrain is associated with treatment response in medication-overuse headache: possible influence of orbitofrontal cortex. J Neurosci 33:15343-15349. https://doi.org/10.1523/JNEUROSCI.3804-12.2013

122. Rapoport AM (2008) Medication overuse headache: awareness, detection and treatment. CNS Drugs 22:995-1004. https://doi.org/10.2165/0023210200822120-00003\r22123

123. Rossi P, Di Lorenzo C, Faroni J et al (2006) Advice alone vs. structured detoxification programmes for medication overuse headache: a prospective, randomized, open-label trial in transformed migraine patients with low medical needs. Cephalalgia 26:1097-1105. https://doi.org/10.1111/j.14682982.2006.01175.x

124. Jonsson $P$, Linde M, Hensing G, Hedenrud T (2012) Sociodemographic differences in medication use, health-care contacts and sickness absence among individuals with medication-overuse headache. J Headache Pain 13: 281-290. https://doi.org/10.1007/s10194-012-0432-y

125. Bekkelund SI, Salvesen R (2002) Patient satisfaction with a neurological specialist consultation for headache. Scand J Prim Health Care 20:157-160. https://doi.org/10.1080/028134302760234609

126. Negro A, Curto M, Lionetto L et al (2017) A critical evaluation on $\mathrm{MOH}$ current treatments. Curr Treat Options Neurol 19:32. https://doi.org/10.1007/ s1 1940-017-0465-2

127. Jonsson P, Jakobsson A, Hensing $G$ et al (2013) Holding on to the indispensable medication- a grounded theory on medication use from the perspective of persons with medication overuse headache. J Headache Pain 14:43. https://doi.org/10.1186/1129

128. Fritsche G, Frettlöh J, Hüppe M et al (2010) Prevention of medication overuse in patients with migraine. Pain 151:404-413. https://doi.org/10. 1016/j.pain.2010.07.032

129. Kristoffersen ES, Straand J, Vetvik KG et al (2015) Brief intervention for medication-overuse headache in primary care. The BIMOH study:a doubleblind pragmatic cluster randomised parallel controlled trial. J Neurol Neurosurg Psychiatry 86:505-512. https://doi.org/10.1136/jnnp-2014-308548

130. Mehuys E, Paemeleire $K$, Van Hees T et al (2012) Self-medication of regular headache: a community pharmacy-based survey. Eur J Neurol 19:10931099. https://doi.org/10.1111/j.1468-1331.2012.03681.x

131. Hedenrud T, Babic N, Jonsson P (2014) Medication overuse headache: selfperceived and actual knowledge among pharmacy staff. Headache 54 : 1019-1025. https://doi.org/10.1111/head.12350

132. Carlsen LN, Westergaard ML, Bisgaard M et al (2017) National awareness campaign to prevent medication-overuse headache in Denmark. Cephalalgia 0:033310241773689. https://doi.org/10.1177/0333102417736898

133. Louter MA, Robbins MS, Terwindt GM (2017) Medication overuse headache: an ongoing debate. Neurology 89:1206-1207. https://doi.org/10.1212/WNL. 0000000000004374

134. Olesen J (2012) Detoxification for medication overuse headache is the primary task. Cephalalgia 32:420-422. https://doi.org/10.1177/ 0333102411431309

135. Zeeberg P, Olesen J, Jensen R (2006) Probable medication-overuse headache: the effect of a 2-month drug-free period. Neurology 66:18941898. https://doi.org/10.1212/01.wnl.0000217914.30994.bd

136. Carlsen LN, Munksgaard SB, Jensen RH, Bendtsen L (2018) Complete detoxification is the most effective treatment of medication-overuse headache: a randomized controlled open-label trial. Cephalalgia 38:225-236. https://doi.org/10.1177/0333102417737779

137. Evers S, Jensen R, European Federation of Neurological Societies (2011) Treatment of medication overuse headache??Guideline of the EFNS headache panel. Eur J Neurol 18:1115-1121. https://doi.org/10.1111/j.1468

138. Kennis K, Kernick D, O'Flynn N (2013) Diagnosis and management of headaches in young people and adults: NICE guideline. Br J Gen Pract 63: 443-445. https://doi.org/10.3399/bjgp13X670895

139. Becker W, Findlay T, Moga C et al (2015) Guideline for primary care management of headache in adults. Can Fam physician Médecin Fam Can 61:670-679

140. Grazzi L, Bussone G (2011) What future for treatment of chronic migraine with medication overuse? Neurol Sci 32:S19-S22. https://doi.org/10.1007/ s10072

141. Katsarava Z, Obermann M (2013) Medication-overuse headache. Curr Opin Neurol 26:276-281. https://doi.org/10.1097/WCO.0b013e328360d596

142. Rossi P, Faroni JV, Nappi G (2011) Short-term effectiveness of simple advice as a withdrawal strategy in simple and complicated medication overuse headache. Eur J Neurol 18:396-401. https://doi.org/10.1111/j. 1468-1331.2010.03157.x

143. Rossi P, Faroni JV, Tassorelli C, Nappi G (2013) Advice alone versus structured detoxification programmes for complicated medication overuse headache $(\mathrm{MOH})$ : a prospective, randomized, open-label trial. J Headache Pain 14:10. https://doi.org/10.1186/1129-2377-14-10

144. Kristoffersen ES, Straand J, Vetvik KG et al (2016) Brief intervention by general practitioners for medication-overuse headache, follow-up after 6 months: a pragmatic cluster-randomised controlled trial. J Neurol 263:344353. https://doi.org/10.1007/s00415-015-7975-1

145. Créac'h C, Frappe P, Cancade M et al (2011) In-patient versus out-patient withdrawal programmes for medication overuse headache: a 2-year randomized trial. Cephalalgia 31:1189-1198. https://doi.org/10.1177/ 0333102411412088 
146. Weatherall MW, Telzerow AJ, Cittadini E et al (2010) Intravenous aspirin (lysine acetylsalicylate) in the inpatient management of headache. Neurology 75(12): 1098-1103. https://doi.org/10.1212 WNL.0b013e3181f39a11

147. Raskin NH (1986) Repetitive intravenous dihydroergotamine as therapy for intractable migraine. Neurology 36:995-997. https://doi.org/10.1212/ WNL.36.7.995

148. Mathew NT (1987) Amelioration of ergotamine withdrawal symptoms with naproxen. Headache J Head Face Pain 27:130-133. https://doi.org/10.1111/j. 1526-4610.1987.hed2703130.x

149. Probyn K, Bowers H, Caldwell F et al (2017) Prognostic factors for chronic headache. Neurology 89:291-301. https://doi.org/10.1212/WNL. 0000000000004112

150. Nagy AJ, Gandhi S, Bhola R, Goadsby PJ (2011) Intravenous dihydroergotamine for inpatient management of refractory primary headaches. Neurology 77(20):1827-1832. https://doi.org/10.1212/WNL. Ob013e3182377dbb

151. Cevoli S, Giannini G, Favoni V et al (2017) Treatment of withdrawal headache in patients with medication overuse headache: a pilot study. J Headache Pain. 18(1):56. https://doi.org/10.1186/s10194-017-0763-9

152. de Goffau MJ, Klaver ARE, Willemsen MG et al (2016) The effectiveness of treatments for patients with medication overuse headache; a systematic review and meta-analysis. J Pain 18:615-627. https://doi.org/10.1016/j.jpain. 2016.12.005

153. Zebenholzer K, Thamer M, Wöber C (2012) Quality of life, depression, and anxiety 6 months after inpatient withdrawal in patients with medication overuse headache: an observational study. Clin J Pain 28:284-290. https:// doi.org/10.1097/AJP.0b013e3182321d35

154. Zeeberg P, Olesen J, Jensen R (2005) Efficacy of multidisciplinary treatment in a tertiary referral headache Centre. Cephalalgia 25:1159-1167. https://doi. org/10.1111/j.1468-2982.2005.00980.x

155. Pijpers JA, Louter MA, De Bruin ME et al (2016) Detoxification in medicationoveruse headache, a retrospective controlled follow-up study: does care by a headache nurse lead to cure? Cephalalgia 36:122-130. https://doi.org/10. 1177/0333102415583146

156. Tassorelli $C$, Jensen $R$, Allena $M$ et al (2014) A consensus protocol for the management of medication-overuse headache: evaluation in a multicentric, multinational study. Cephalalgia 34:645-655. https://doi.org/10.1177/ 0333102414521508

157. Rossi P, Jensen R, Nappi G, Allena M (2009) A narrative review on the management of medication overuse headache: the steep road from experience to evidence. J Headache Pain 10:407-417. https://doi.org/10. 1007/s10194-009-0159-6

158. Chiang C-C, Schwedt TJ, Wang S-J, Dodick DW (2016) Treatment of medication-overuse headache: a systematic review. Cephalalgia 36:371-386. https://doi.org/10.1177/0333102415593088

159. Martelletti P (2018) The journey from genetic predisposition to medication overuse headache to its acquisition as sequela of chronic migraine. J Headache Pain 19:2. https://doi.org/10.1186/s10194-017-0830-2

160. Probyn K, Bowers H, Caldwell F et al (2017) Prognostic factors for chronic headache: a systematic review. Neurology 89:291-301

161. Hagen K, Jensen R, Bøe MG, Stovner LJ (2010) Medication overuse headache: a critical review of end points in recent follow-up studies. J Headache Pain 11:373-377. https://doi.org/10.1007/s10194-010-0221-4

162. Diener HC, Dichgans J, Scholz E et al (1989) Analgesic-induced chronic headache: long-term results of withdrawal therapy. J Neurol 236:9-14. https://doi.org/10.1007/BF00314210

163. Suhr B, Evers S, Bauer B et al (1999) Drug-induced headache: long-term results of stationary versus ambulatory withdrawal therapy. Cephalalgia 19: 44-49

164. Schnider P, Aull S, Baumgartner C et al (1996) Long-term outcome of patients with headache and drug abuse after inpatient withdrawal: five-year follow-up. Cephalalgia 16:481-485

165. Fritsche G, Eberl A, Katsarava Z et al (2001) Drug-induced headache: longterm follow-up of withdrawal therapy and persistence of drug misuse. Eur Neurol 45:229-235. https://doi.org/10.1159/000052134

166. Grazzi L, Andrasik F, D'Amico D et al (2002) Behavioral and pharmacologic treatment of transformed migraine with analgesic overuse: outcome at 3 years. Headache 42:483-490. https://doi.org/10. 1046/j.1526-4610.2002.02123.x

167. Zidverc-Trajkovic J, Pekmezovic T, Jovanovic Z et al (2007) Medication overuse headache: clinical features predicting treatment outcome at 1-year follow-up. Cephalalgia 27:1219-1225. https://doi.org/10.1111/j.1468-2982. 2007.01432.x

168. Bigal ME, Rapoport AM, Sheftell FD et al (2004) Transformed migraine and medication overuse in a tertiary headache Centre-clinical characteristics and treatment outcomes. Cephalalgia an Int J headache 24:483-490. https://doi.org/10.1111/j.1468-2982.2004.00691.x

169. Sances G, Galli F, Anastasi S et al (2010) Medication-overuse headache and personality: a controlled study by means of the MMPI-2: research submission. Headache 50:198-209. https://doi.org/10.1111/j.1526-4610.2009. 01593.x

170. Bøe MG, Salvesen R, Mygland $\AA$ (2009) Chronic daily headache with medication overuse: predictors of outcome 1 year after withdrawal therapy. Eur J Neurol 16:705-712. https://doi.org/10.1111/j.1468-1331.2009.02571.x

171. Bøe MG, Thortveit E, Vatne A, Mygland $\AA$ (2017) Chronic headache with medication overuse: long-term prognosis after withdrawal therapy. Cephalalgia 37:1215-1221. https://doi.org/10.1177/0333102416672493

172. Zidverc-Trajkovic JJ, Pekmezovic T, Jovanovic Z et al (2016) Long-term predictors of remission in patients treated for medication-overuse headache at a specialized headache center: a prospective cohort study. Cephalalgia 0: 1-9. https://doi.org/10.1177/0333102416683918

173. Evers S, Suhr B, Bauer B et al (1999) A retrospective long-term analysis of the epidemiology and features of drug-induced headache. J Neurol 246: 802-809. https://doi.org/10.1007/s004150050458

174. Pini L-A, Cicero A, Sandrini M (2001) Long-term follow-up of patients treated for chronic headache with analgesic overuse. Cephalalgia 21:878883. https://doi.org/10.1046/j.1468-2982.2001.00288x

175. Tribl GG, Schnider $P$, Wöber $C$ et al (2001) Are there predictive factors for long-term outcome after withdrawal in drug-induced chronic daily headache? Cephalalgia 21:691-696

176. Katsarava Z, Muessig M, Dzagnidze A et al (2005) Medication overuse headache: rates and predictors for relapse in a 4-year prospective study. Cephalalgia 25:12-15. https://doi.org/10.1111/j.1468-2982.2004.00789.x

177. Fontanillas N, Colás R, Muñoz P et al (2010) Long-term evolution of chronic daily headache with medication overuse in the general population. Headache 50:981-988. https://doi.org/10.1111/j.1526-4610.2010.01629.x

178. Zeeberg P, Olesen J, Jensen R (2006) Discontinuation of medication overuse in headache patients: recovery of therapeutic responsiveness. Cephalalgia 26:1192-1198. https://doi.org/10.1111/j.1468-2982.2006.01190.x

179. Katsarava Z, Limmroth V, Finke M et al (2003) Rates and predictors for relapse in medication overuse headache: a 1-year prospective study. Neurology 60:1682-1683

180. Tfelt-Hansen P, Krabbe AÆE (1981) Ergotamine abuse. Do patients benefit from withdrawal? Cephalalgia 1:29-32. https://doi.org/10.1111/j.1468-2982 1981.tb00005.x

181. Sances G, Ghiotto N, Galli F et al (2010) Risk factors in medication-overuse headache: a 1-year follow-up study (care II protocol). Cephalalgia 30:329336. https://doi.org/10.1111/j.1468-2982.2009.01934.x

182. Jensen $\mathrm{RH}$, Bendtsen $\mathrm{L}$ (2008) Medication overuse headache in Scandinavia. Cephalalgia 28:1237-1239

183. Serrano D, Lipton RB, Scher Al et al (2017) Fluctuations in episodic and chronic migraine status over the course of 1 year: implications for diagnosis, treatment and clinical trial design. J Headache Pain 18:101. https://doi.org/ 10.1186/s10194-017-0787-1

184. Scher Al, Rizzoli PB, Loder EW (2017) Medication overuse headache an entrenched idea in need of scrutiny. Neurology 89:1296-1304. https://doi. org/10.1212/WNL.0000000000004371

185. Solomon M, Nahas SJ, Segal JZ, Young WB (2011) Medication adaptation headache. Cephalalgia 31:515-517. https://doi.org/10.1177/ 0333102410387678 